\title{
Os cuidados imediatos prestados ao recém-nascido e a promoção do vínculo mãe-bebê
}

Enfermeira. Especialista em Neonatologia pela Faculdade de Enfermagem, Universidade Estadual do Rio de Janeiro (UERJ) Enfermeira do Hospital dos Servidores do Estado do Rio de Janeiro, Rio de Janeiro, RJ, Brasil. dannicarvalho2003@ yahoo.com

II Enfermeira. Especialista em Nenonatologia pela Faculdade Enfermagem, Universidade Estadual do Rio de Janeiro (UERJ). Enfermeira do Hospital dos Italianos, Rio de Janeiro, RJ, Brasil. Natalia2005@ click21.com.br

III Doutora em Enfermagem. Professora Adjunta da Faculdade de Enfermagem, Universidade Estadual do Rio de Janeiro (UERJ). Enfermeira Obstétrica do Hospital Universitário Gaffrée e

Guinle da UNI-RIO Rio de Janeiro, RJ, Brasil.spindola@ predialnet.com.br

\section{RESUMO}

Trata-se de um estudo descritivo em abordagem qualitativa, com objetivo de compreender como o momento do parto foi percebido pelas mães e de que maneira as ações dos profissionais contribuíram para facilitar sua aproximação ao recém-nascido. Foram entrevistadas 25 multíparas, de uma maternidade pública no Rio de Janeiro, que tiveram recém-nascidos de baixo risco e parto normal. A análise de conteúdo dos relatos revelou que os cuidados imediatos prestados ao bebê, distante do olhar materno, geram nas mães preocupação, sensação de afastamento e medo da separação do bebê. Algumas mulheres, todavia, valorizaram a assistência intervencionista por acreditar que estes cuidados são indispensáveis para garantir a integridade física de seus filhos. Podemos concluir que, embora valorizem a aproximação a seus bebês no pós-parto imediato, as mães investigadas não conseguem perceber a interferência desse contato inicial no estabelecimento do vínculo precoce em decorrência de inúmeros fatores, dentre eles, os socioculturais.

\section{DESCRITORES}

Parto.

Recém-nascido.

Enfermagem neonatal.

Assistência perinatal.

\section{ABSTRACT}

This is a descriptive study with a qualitative approach aimed at understanding how mothers perceived the moment of childbirth and how the actions of the professionals contributed to facilitate their closeness to their babies. Twenty-five multiparous women in a public maternity in Rio de Janeiro who had had low risk, normal labor deliveries were interviewed. The analysis of the reports revealed that immediate care given to babies away from their mother's view generates in mothers concern, a feeling of distance and fear of being separated from the baby. However, some women valued the interventionist assistance because they believe that this care is indispensable to ensure their child's physical integrity. Although they valued closeness to their babies in the immediate post-labor period, the surveyed mothers failed to notice the interference of this initial contact for the establishment of an early bond because of a number of factors, among them social-cultural ones.

\section{KEY WORDS}

Parturition.

Infant, newborn.

Neonatal nursing.

Perinatal care.

\section{RESUMEN}

Se trata de un estudio descriptivo en abordaje cualitativa, con objetivo de comprender como el momento del parto fue percibido por las madres y de que manera las acciones de los profesionales contribuyeron para facilitar su aproximación al recién-nacido. Fueron entrevistadas 25 multíparas, de una maternidad pública en Rio de Janeiro, que tuvieron recién-nacidos de bajo riesgo y parto normal. La análisis del contenido de los relatos rebeló que los cuidados inmediatos prestados al bebé, distante de la mirada materna, generan en las madres preocupación, sensación de alejamiento y miedo de la separación del bebé. Algunas mujeres, todavía, valorizaron la asistencia intervencionista por creer que estos cuidados son indispensables para garantizar la integridad física de sus hijos. Podemos concluir que, mismo que valoricen la aproximación a sus bebés en el pos-parto inmediato, las madres investigadas no consiguen percibir la interferencia de ese contacto inicial en el establecimiento del vínculo precoz en descorrimiento de innúmeros factores, entre ellos, los socioculturales.

\section{DESCRIPTORES \\ Parto. \\ Recién nacido. \\ Enfermería neonatal. \\ Atención perinatal.}




\section{CONSIDERAÇÕES INICIAIS}

O contato físico muito precoce entre mãe e filho tem importância prioritária na visão humanizada de cuidados ao bebê ainda na sala de parto. A fim de se evitar separações desnecessárias entre o binômio, o que poderia prejudicar o aleitamento materno e a aproximação ao bebê, é importante reduzir ao estritamente necessário os procedimentos realizados no pós-parto imediato, quando se tratar de um bebê de baixo risco.

O objeto deste estudo é a influência dos cuidados imediatos prestados ao recém-nascido de baixo risco no estabelecimento do vínculo precoce entre a mãe e o bebê. A maneira como o bebê nasce, seja com suavidade, sofrimento, violência, tranqüilidade ou paciência, terá implicações diretas na efetividade do vínculo com sua mãe ${ }^{(1)}$.

Foi desenvolvida uma filosofia de assistência ao parto, denominada humanização do parto e nascimento, cuja preocupação essencial é acolher bem o recém-nascido (RN), suavizando o impacto da diferença entre o mundo intra e extra-uterino. É preconizado o emprego de uma luz difusa na sala de parto, silêncio, ambiente menos frio e tranqüilo, uma música suave e o contato corporal imediato entre a mãe e o RN. Este deve ser colocado sobre o ventre da mãe logo após o nascimento, sendo acariciado por ela e somente após alguns minutos corta-se o cordão umbilical ${ }^{(2)}$.

Neste sentido, autores ${ }^{(3)}$ afirmam que em condições satisfatórias para a mãe e o concepto, logo após o parto, deve-se estimular o contato físico entre ambos e a sucção precoce por contribuírem para o estabelecimento ou continuidade do vínculo além de favorecer a contratilidade uterina e auxiliar no processo de amamentação.

A humanização do atendimento aos usuários do Sistema Único de Saúde é uma das metas do Ministério da Saúde. O Programa de Humanização do Pré-Natal e do Nascimento (PHPN) estabeleceu os princípios da atenção a ser prestada nos diferentes níveis de atenção à saúde pública e garantiu à mulher o direito de dar à luz recebendo uma assistência humanizada e de boa qualidade ${ }^{(4)}$. Na década de 90 , no Rio de Janeiro, a secretaria municipal iniciou a implantação da Política de Humanização do Parto e Nascimento tendo como uma das estratégias a hierarquização da assistência ao parto, com a inclusão da assistência aos partos de baixo risco por enfermeiras obstétricas conforme o exemplo de alguns países europeus ${ }^{(5)}$.

Desenvolvendo atividades práticas no centro obstétrico de uma instituição pública no município do Rio de Janeiro, que adota os princípios da humanização do atendimento à mulher no pré-natal e nascimento, tivemos a oportunidade de observar que somente a implantação do PNHP não resulta, necessariamente, na modificação do modelo de assistência que está associado a diversos fatores, dentre eles os estruturais e organizacionais. Acreditamos que o parto é um momento especial para a gestante e que os profissionais de saúde devem atuar como facilitadores desse processo oferecendo suporte emocional e segurança para a mulher e sua família, contribuindo para a formação do vínculo mãe-bebê.

Tendo como foco de atenção os cuidados imediatos prestados ao RN na sala de parto e sua influência no estabelecimento do vínculo entre a mãe e o bebê, definimos como objetivos do estudo: Compreender como o momento do parto foi percebido pelas mães e de que maneira as ações dos profissionais facilitaram ou dificultaram a aproximação entre a mãe e o RN.

\section{OS CUIDADOS IMEDIATOS AO RN E SUA INFLUÊNCIA NA PROMOÇÃO DO VÍNCULO}

As ações dos profissionais de saúde em relação aos cuidados prestados ao interferir

negativamente na aproximação precoce entre a mãe e o bebê.
Os cuidados prestados ao RN imediatamente após o parto são essenciais para a adaptação do bebê diminuindo a morbi-mortalidade neonatal. O delicado momento de transição do meio intra para o extra-uterino é marcado por inúmeras mudanças para a criança. $\mathrm{O}$ meio intra-uterino proporciona um ambiente de aconchego, de temperatura e luminosidade constantes, os ruídos são ouvidos suavemente, não necessitando de esforço para realizar as funções vitais. Com o nascimento o bebê vai se adaptando gradualmente ao meio extrauterino superando as dificuldades inerentes ao seu desenvolvimento.

A primeira hora de vida de um bebê é um período denominado de inatividade alerta do RN que dura em média quarenta minutos ${ }^{(1)}$. Esses momentos iniciais são uma fase sensível, precursora de apego e a primeira oportunidade da mãe ser sensibilizada pelo seu bebê, nesse contexto destaca-se a importância que a realização de procedimentos assume na sala de parto. O profissional de saúde envolvido no nascimento é uma figura facilitadora ou não deste processo, possibilitando a aproximação precoce entre a mãe e seu filho para que o vínculo se estabeleça. Nesta concepção, as ações dos profissionais de saúde no pós-parto imediato em relação aos cuidados prestados ao recém-nascido podem interferir negativamente na aproximação precoce entre a mãe e o bebê $\hat{e}^{(1)}$.

Nos modelos tecnocrático e humanista de assistência ao parto e nascimento, adotam-se procedimentos distintos para assistir à parturiente e o RN. O modelo tecnocrático emprega os recursos tecnológicos disponíveis, valoriza a hierarquia, a burocracia e visualizam o corpo como uma máqui- 
$\mathrm{na}^{(6)}$. No modelo humanista de assistência o corpo é percebido como um organismo havendo união entre o corpo e a mente. Existe a conexão do paciente aos seus aspectos múltiplos (família, sociedade, saúde) e aos profissionais, valorizando-se a consideração, bondade e respeito ${ }^{(6)}$.

Os cuidados imediatos podem ser efetivados de diferentes formas de acordo com o tipo de modelo de assistência adotado. Após o nascimento, sempre que for possível, o bebê deverá ser encaminhado para sua mãe. A secção do cordão umbilical imediatamente após o nascimento ocasiona a separação do binômio e impede o contato e aproximação precoce de $\operatorname{ambos}^{(7)}$. No modelo de assistência humanizada $^{(8)}$ observa-se que apesar da secção do cordão umbilical ser um cuidado imediato, desde que mãe e bebê estejam em boas condições, não necessita ser realizado logo após o nascimento, podendo-se preservar o contato precoce entre a mãe e o RN.

No modelo medicalizado no momento em que o bebê nasce, geralmente, o cordão umbilical é cortado, ergue-se a criança para mostrá-la à mãe e ela é levada para o berço aquecido, não havendo qualquer tipo de aproximação e interação entre o binômio, sendo impossibilitados de dar seguimento ao vínculo precoce que se estabelece logo após o nascimento ${ }^{(3)}$.

Em relação à manutenção da temperatura corpórea no modelo humanista prioriza-se o aquecimento do $\mathrm{RN}$, no contato pele a pele com a mãe em um quarto aquecido e, se necessário, cobri-lo com um cobertor ${ }^{(8)}$, na assistência intervencionista é preconizado que a perda calórica é minimizada secando-se rapidamente a pele e o cabelo do RN colocandoo em ambiente aquecido ${ }^{(9)}$.

Outro tipo de contato importante que se estabelece entre a mãe e o RN é o visual. Um estudo demonstrou a existência de movimentos oculares de bebês de zero a seis meses verificando-se a existência de uma fixação rudimentar desde o primeiro dia de vida que se estabilizava em torno do quinto $\mathrm{dia}^{(2)}$. Quando mãe é a pessoa que está mais em contato com o bebê e que também lhe oferece outras estimulações, o primeiro objeto atraente que surge no campo visual do RN é o rosto da mãe. Os cuidados maternos formam a base da vida emocional e de relacionamento do $\mathrm{RN}^{(2)}$.

A vertente humanizadora de assistência ao parto e nascimento preconiza que os profissionais devem estimular a aproximação entre a mãe e o bebê no pós-parto imediato, em contato pele a pele. Os cuidados podem ser prestados mantendo-se e respeitando este momento de interação para que se favoreça o estabelecimento precoce do vínculo. A importância da proximidade e do toque entre o binômio é relata$\mathrm{da}^{(7)}$ mencionando pesquisas que evidenciam as vantagens no estado de saúde, atenção e responsividade dos filhos que foram carregados no colo em comparação com os que não o foram. É relatado que os bebês acariciados pela mãe logo após o nascimento apresentavam uma incidência menor de resfriados, gripes, vômitos, diarréias em relação aos que foram desprovidos desse ato ${ }^{(7)}$.

A existência de um período sensível, imediatamente após o parto, foi evidenciada em estudo ${ }^{(10)}$. Durante esta fase, um contato intenso e ininterrupto da mãe com o seu bebê proporcionam a receptividade mais precoce da mãe e sua adaptação, dando prosseguimento ao vínculo que começou a ser estabelecido já na vida intra-uterina. Outros benefícios deste contato inicial incluem o fato de a amamentação ocorrer mais cedo e o estreitamento da atração emocional.

\section{MÉTODO}

Estudo do tipo descritivo em abordagem qualitativa, realizado em uma maternidade pública no município do Rio de Janeiro em que atuam médicos e enfermeiros obstetras e são adotados os dois modelos de assistência ao parto (tecnocrático e humanista). A pesquisa foi aprovada pelo Comitê de Ética da Universidade do Estado do Rio de Janeiro, tendo-se solicitado autorização à chefia da unidade para a entrada em campo (Processo CEP n. 1106/2005).

Num primeiro momento foram selecionados os prontuários das puérperas de parto normal, cujos bebês tiveram APGAR entre 8-10, caracterizando um RN de baixo risco, de mães multíparas, em função de sua vivência com a parturição e o nascimento. Abordamos as mulheres no dia seguinte ao parto, questionando-as quanto ao interesse em participar da pesquisa. Àquelas que concordaram foi apresentado o Termo de Consentimento Livre e Esclarecido e realizado uma entrevista semi-estruturada, com auxílio de um gravador, tendo quatro questões abertas (Fale-me sobre o momento do seu parto; Após o nascimento o que foi feito com o RN; O que significou para você os cuidados prestados ao $R N$ no momento do parto; Os cuidados prestados ao RN no momento do parto interferiram na sua aproximação a ele?), em fevereiro e março de 2005. O instrumento foi testado, previamente, para verificar possíveis incorreções e falhas na técnica da entrevista, por duas das pesquisadoras que, após os ajustes necessários procederam à coleta em local reservado. Duas das pesquisadoras, na ocasião das en-trevistas, desenvolviam práticas assistenciais na maternidade em que ocorreu o estudo, o que facilitou a aproximação às depoentes.

Alguns dados foram levantados de seus prontuários como nível de escolaridade, idade, paridade, procedência e número de consultas de pré-natal permitindo delinear o seu perfil. No grupo investigado três mulheres tinham idade inferior a 19 anos, para que fossem incluídas na pesquisa solicitou-se autorização a um responsável e que ambos assinassem o Termo de Consentimento. Durante as entrevistas notamos que as mães verbalizavam com dificuldade sua percepção do momento do parto e aproximação ao recém-nasci- 
do. Mostravam-se tímidas e expressavam-se com poucas palavras, embora estimuladas a falar pelas pesquisadoras durante os relatos. Foram realizadas 25 entrevistas em função da saturação dos depoimentos. Para preservar o anonimato das mulheres as entrevistas foram numeradas seqüencialmente.

As entrevistas foram transcritas e analisadas, com a técnica de análise de conteúdo, procedendo-se uma análise temática com os seguintes passos: pré-análise; exploração do material e tratamento dos resultados; interferência e interpretação ${ }^{(11)}$. Ocorreu a seleção dos documentos importantes para análise (pré-análise). As transcrições foram submetidas à leitura e releitura e, tendo-se definido as unidades de registro no texto, marcando o início e o final de cada uma delas no texto analisado (exploração do material). Identificamos e nomeamos os temas, ou unidades de significação, associados ao objeto de estudo (tratamento dos resulta$d o s)$. Em seguida quantificamos os temas, bem como, definimos e nomeamos as categorias, que consiste em agrupar os temas em conjuntos maiores do que o próprio tema e atribuir nomes para as categorias definidas em função do que os temas expressam (tratamento dos resultados, interferência e interpretação). A partir da análise dos relatos emergiram as categorias: 1- $\mathrm{O}$ significado do momento do parto (56 unidades de registro e 23,5\%), 2- Os cuidados prestados ao RN sob a ótica da mãe (62 unidades de registro e 26,1\%) e 3A interferência dos cuidados prestados ao RN na aproximação mãe-bebê (120 unidades de registro e 50,3\%) (interpretação dos achados). No momento, apresentamos a análise de duas categorias.

\section{RESULTADOS}

\section{E ANÁLISE DOS RELATOS}

O perfil das entrevistadas era o seguinte: quanto à idade 10 mulheres tinham entre quinze e vinte anos, sete entre vinte e um e vinte e cinco e oito acima de vinte e cinco anos; em relação ao nível de escolaridade três mães eram analfabetas, 13 tinham o ensino fundamental incompleto, sete o ensino fundamental completo e duas o ensino médio; quanto à realização de consultas de pré-natal 15 mulheres tiveram de zero a três consultas, oito de quatro a seis consultas e duas mais de seis consultas; em relação ao número de gestações 19 mães tiveram duas ou três e seis de quatro a seis gestações.

$\mathrm{Na}$ análise dos relatos emergiram três categorias, dentre elas: Os cuidados prestados ao RN sob a ótica da mãe e A interferência dos cuidados prestados ao RN na aproximação mãe-bebê, descritas a seguir.

\section{Os cuidados prestados ao RN sob a ótica da mãe}

Conforme mencionamos anteriormente, a instituição onde a investigação ocorreu adota os dois modelos de assistên- cia ao parto (tecnocrático e humanista). A equipe que atua no serviço é composta por médicos, enfermeiras obstétricas, neonatologistas e auxiliares de enfermagem. Como o número de profissionais ainda é insuficiente (duas enfermeiras para cada turno de 12 horas), nem todas as entrevistadas foram assistidas no mesmo modelo de assistência como pudemos perceber em seus relatos. Por este motivo, as puérperas referiram que imediatamente após o nascimento seus bebês foram levados a outro local para a realização de cuidados. Vale destacar que em seus depoimentos as mães revelaram desconhecer o que seria feito com seus bebês. Essa prática, ainda presente, gerava nas mulheres ansiedade e expectativa como podemos observar nos seguintes relatos:

\section{Ah... logo pegaram ela pra limpa e demoraram muito tempo pra coloca ela perto de mim aí eu fiquei até preocupada (Puérpera 15).}

Foram limpar, né? Levaram para o lado... eu fiquei com medo, a gente fica com medo de troca de bebê...(Puérpera 03).

Ao analisarmos esses recortes de depoimentos podemos notar que na prestação de assistência ao parto e nascimento houve priorização do modelo tecnocrático, com a separação entre a mãe e o bebê para realizar cuidados ao recém nascido. Todavia, este tempo em que o binômio esteve separado, se constituía em um período sensível propício para a aproximação precoce e efetiva entre $\operatorname{ambos}^{(6)}$. O período sensível no RN está presente na primeira hora após o nascimento por um período de 45 a 60 minutos, no qual enxerga e orienta a cabeça na direção das vozes das pessoas. Assim, os minutos iniciais de vida extra-uterina são, portanto, ideais para o bebê estabelecer contato com os pais ${ }^{(6)}$. Em condições satisfatórias para a mãe e bebê, autores ${ }^{(3)}$ lembram a importância de se proporcionar o contato físico entre ambos e a sucção precoce que contribuem para o estabelecimento ou continuidade do vínculo e estimulam o aleitamento.

Nos relatos podemos perceber que existe uma relação entre o tipo de cuidado prestado à mulher e $\mathrm{RN}$ e a aproximação precoce, destacando-se a importância da assistência humanizada no parto e nascimento que prioriza o contato inicial de toque e aconchego entre ambos, conforme salientam os relatos:

Assim que ela nasceu veio pra cima de mim, achei muito gostoso... e com certeza une mais os dois, mãe e filho (Puérpera 21).

Eu tive mais carinho assim... já estava amando a minha filha, então dali eu passei a amar mais ainda (Puérpera 14).

As mulheres em suas descrições revelaram que o fato de poder desfrutar imediatamente após o parto o contato com seus filhos faz com que se sintam plenas e realizadas, em condições de proporcionar amor e aconchego, o que favorece a união de ambos. $\mathrm{O}$ contato epidérmico entre mãe e 
bebê é muito importante, pois é através dele que o concepto começa a se integrar com o mundo e se preparar para experiências até então desconhecidas ${ }^{(6)}$. É este contato corporal que constitui a origem principal do bem estar, segurança e afetividade, dando ao bebê a capacidade de procurar novas vivências. Em estudo ${ }^{(12)}$ realizado com mães adolescentes foi verificada a importância de favorecer o contato e aproximação entre ambos, logo após o nascimento, para que se estabeleça o vínculo tendo-se constatado em todas as observações realizadas na sala de parto.

Entretanto, as mulheres assistidas no modelo tecnocrático, verbalizaram sua satisfação e confiança, conforme podemos observar nos fragmentos de relatos:

\begin{abstract}
Levaram pra cuidar dela e depois trouxeram para eu ficar perto dela [...] até que eu gostei estava preocupada para ver se não afetou nada (Puérpera 04).
\end{abstract}

Levaram ele, limparam, cuidaram dele [..]) significou que ele está bem né?, eles cuidaram direito (Puérpera 20).

Levaram pra limpar... significou muita coisa, achei legal como trataram dela. Foram bastante cuidadoso (Puérpera 06).

Estes depoimentos refletem uma grande preocupação das mães com a saúde e integridade física de seus filhos, visualizando nos cuidados prestados a garantia de sua preservação. No caso específico da Puérpera 04, que apresentou ameaças de abortamento durante a gestação, sua preocupação estava relacionada com o nível de comprometimento desses episódios na saúde do bebê. Outras mulheres, entretanto, expressaram um enorme desejo de ficar com seus bebês antes de qualquer tipo de intervenção. Desta forma valorizaram a importância da aproximação e do toque logo após o nascimento, conforme preconiza a assistência humanizada do parto, para que pudessem manifestar toda a sua emoção pelo contato, olhar e aconchego.

Cortando o cordão ele já estava no meu colo [...] Ah, foi maravilhoso porque é o momento mais esperado da mãe, o neném no colo (Puérpera 08).

Botaram ela pra mim segurar, pra mim ver ela. Eu fiquei contente, abracei ela. É muito bom ter esse contato logo assim de cara (Puérpera 11).

É o primeiro contato que a gente tem com o bebê, o primeiro toque, pele a pele...(Puérpera 19).

Nestas descrições podemos notar o desejo e a necessidade de sentir seus bebês logo após o nascimento, para que possam estabelecer contato físico, pele a pele e assim transmitirem carinho e amor já que aguardaram, ansiosamente, por este momento no processo de gestar. Manter mãe e bebê juntos logo após o nascimento parece iniciar e estimular a operação de mecanismos sensoriais, hormonais, fisiológicos, imunológicos e comportamentais conhecidos, que provavelmente unem os pais aos bebês ${ }^{(13)}$. A sequiência de interações entre a mãe e o bebê, durante este período, ligaos um ao outro e assegura o desenvolvimento posterior do apego.

Na vivência do parto humanizado de mães adolescentes foi observado ${ }^{(12)}$ que o corpo do bebê junto ao corpo da mãe parece ser uma só pessoa em seu primeiro contato, parecendo que agiam sincronicamente, que respiravam numa cadência harmônica, olhavam-se, conheceram-se pelo toque, cheiro e entregavam-se passivamente um ao outro sendo dissipado naquele encontro toda turbulência do momento do parto pelo prazer de estarem juntos ${ }^{(12)}$.

Outro fator de grande importância para o estímulo da interação, e conseqüente aproximação entre ambos, é permitir que haja contato do bebê com o seio materno. Mesmo que ele não seja amamentado, neste momento é válido que sinta o cheiro, ou consiga lamber o mamilo de sua mãe. Para que ocorra a amamentação nos primeiros momentos da vida extra-uterina, os profissionais necessitam criar condições que estimulem os sentidos do bebê, pois ele sabe como buscar e encontrar os seios de sua mãe quase que imediatamente $^{(8)}$.

Vale considerar que os RNs deste estudo nasceram em boas condições de vitalidade (apgar 8-10) e poderiam permanecer com suas mães, conforme as recomendações do programa de humanização do parto. Entretanto, em estudo $^{(14)}$ realizado num Centro de Parto Normal, que adota as recomendações do Ministério da Saúde, verificou-se que $6 \%$ dos RNs (em 100 nascimentos) apresentaram quadro de desconforto respiratório e foram transferidos para UTI neonatal, denotando a importância da capacitação dos profissionais de saúde para o atendimento dos RNs.

\section{A interferência dos cuidados prestados ao $R N$ na aproximação mãe-beb̂}

Os cuidados prestados ao bebê na ocasião do parto e as sensações provenientes desse momento têm um significado importante para as mães. A aproximação (ou não) de ambos no pós-parto imediato fica na dependência da conduta do profissional que assiste a mulher no processo de parturição, de suas crenças e valores, como também da política institucional vigente conforme os relatos clarificam:

\section{Primeiro colocaram em cima de mim pra abraçar e beijar, depois foram cuidar dele, a limpeza da criança, os cuidados...(Puérpera 05). \\ Cortando o cordão ele já estava no meu colo. (Puérpera 08) \\ Levaram pra limpar. Me mostraram e levaram, não coloca- ram em cima de mim, não (Puérpera 15).}

Fica evidente nesses relatos que embora os RNs fossem de baixo risco e tivessem nascido em boas condições, podendo estar com suas mães no pós-parto imediato, esta 
aproximação inicial fica condicionada ao profissional que a assiste nesta ocasião. Vale ressaltar, todavia, que as mulheres tiveram seus filhos numa instituição que vem adotando a política de humanização do parto e nascimento, entretanto a mudança de paradigma, crenças e práticas envolve uma série de fatores. Discutindo a implantação da política de humanização do parto e nascimento é referido ${ }^{(5)}$ que esta modalidade de assistência é influenciada pelo modelo organizacional, do envolvimento e aderência dos gerentes à proposta e da capacitação e sensibilidade dos profissionais, sendo, em última instância, atrelada à subjetividade do relacionamento pessoal entre a mulher e o profissional de saúde. O modelo tradicional de assistência ao parto e nascimento, entretanto, desperta nas mães os sentimentos mais diversificados, gerando incertezas e medos:

\section{Queria amamentar, cuidar... fiquei muito ansiosa (Puérpera 09).}

Foram limpar...levaram pro lado e eu fiquei olhando sempre porque a gente fica com medo de troca de bebê. Fiquei contando os dedos... eu fiquei com medo...(Puérpera 03).

Logo pegaram ela pra limpar e demoraram muito tempo pra colocar ela perto de mim... foi ruim porque eu fiquei preocupada, queria vê-la...(Puérpera 18).

Nestes relatos podemos perceber o receio dessas mães com a troca de bebês, fato que muito preocupa as mulheres pela ocorrência em algumas instituições em nosso país, como, também, a vontade de estar com seus filhos e constatar, pelo toque e olhar, que eram perfeitos, saudáveis vivenciando de forma plena aquele momento tão esperado. As mulheres assistidas segundo a proposta do parto humanizado conseguem expressar o significado deste momento:

Esse contato logo assim de cara facilita porque aí ela já começa a me conhecer... desde pequenininha, desde a hora que nasce (Puérpera 11).

... ele ficou um pouquinho comigo... é importante, foi muito bom... porque ele sente o nosso cheiro, o cheiro da mãe que ele já conhece já (Puérpera 20).

... ele ficou um pouco comigo... foi muito bom, senti o calorzinho do meu filho...é bom porque o neném já conhece, já fica conhecendo o calorzinho da mãe...(Puérpera 16).

Em seus relatos as mães explicitam sua emoção em relação ao momento do parto e o contato precoce ao seu filho. $\mathrm{O}$ tipo de assistência recebida transparece em suas falas e nas sensações descritas denotando o significado deste momento para a promoção da aproximação entre a mãe e o bebê. Em estudo $^{(15)}$ que avaliou a relação entre a mãe e o bebê no pósparto evidenciou-se que o contato pele a pele entre ambos, de forma contínua por pelo menos 20 minutos, a partir do nascimento e o estímulo ao aleitamento espontâneo na primeira hora de vida do RN gera nas mulheres uma emoção que interfere no vínculo da relação mãe-bebê.
No entanto nem todas as mães percebem este momento com esta conotação. Além de verbalizarem desconhecer a importância desse contato inicial para a promoção da aproximação precoce a seus conceptos, mostram-se indiferentes às modalidades de assistência ao parto e nascimento não conseguindo visualizar a distinção entre os modelos (tecnocrático ou humanista) e a relação destes para a mãe e o bebê, conforme os relatos clarificam:

Não acho que isso interfere, para mim é tudo a mesma coisa, sendo meu filho...(Puérpera 01).

... ele foi levado...precisava ser limpo... acho que influencia mas não é tão importante assim não (Puérpera 10).

Acho que não interfere porque ele precisava ser limpo, de cuidados... se eu estiver olhando não me importo que levem não (Puérpera 03).

É acho que até tem influência, ...acho que não sei explicar. (Puérpera 24).

Não! Acho que não tem nada a ver (Puérpera 06).

Nesses relatos fica evidente que essas mães desconhecem as ações preconizadas pelo Ministério da Saúde para o parto de baixo risco. Esta constatação, todavia, pode estar relacionada a diversos fatores, dentre eles a falta de esclarecimentos acerca de seus direitos enquanto mulher e mãe de um RN de baixo risco; o número insuficiente de consultas de pré-natal realizadas ( 15 mulheres tiveram de zero a três consultas) ocasião em que seriam orientadas em relação às condutas no parto e rotinas da instituição; o perfil sóciodemográfico das mesmas (baixa escolaridade e nível socioeconômico) que contribui para agravar suas limitações e modelam seu comportamento aceitando as determinações sem questionar. Temos consciência de que a associação desses fatores acaba contribuindo, de maneira significativa, para a exclusão social dessas mulheres, que não reivindicam seus direitos e aceitam com passividade as determinações das instituições de saúde. Um estudo ${ }^{(16)}$ realizado num centro obstétrico de Santa Catarina constatou que, em sua maioria, as mulheres desconhecem as ações preconizadas pelo Ministério da Saúde, ficando satisfeitas com o atendimento que recebem. Acreditam os autores ${ }^{(16)}$ que caso as mulheres fossem cientes de seus direitos, talvez fossem mais exigentes, atuantes e menos dominadas.

Para o Ministério da Saúde o início de todo o processo do nascer saudável está na assistência ao pré-natal ocasião em que os profissionais de saúde devem esclarecer a gestante e sua família sobre o processo de gestar e parir, numa concepção humanizada de assistência ${ }^{(4)}$. Ressalta a importância da mulher e seu acompanhante serem preparados para o momento do parto e poderem vivenciá-los com mais tranqüilidade e participação, sendo o nascimento visualizado como um momento da família. 


\section{CONSIDERAÇÕES FINAIS}

Este estudo teve a proposta de compreender como o momento do parto foi percebido pelas mães e de que maneira as ações dos profissionais contribuíram para facilitar sua aproximação ao recém-nascido. Os relatos revelaram que a assistência à mulher no momento do parto assume um significado especial, sendo percebida de maneira positiva quando as mulheres são assistidas no modelo humanista, ocasião em que se favorece a aproximação precoce entre a mãe e o bebê. Todavia, nem todas as entrevistadas vivenciaram o momento do parto nas mesmas condições e intensidade.

Em relação aos cuidados imediatos prestados ao RN, por ocasião do parto, foi revelado que para algumas mães o fato desses cuidados serem prestados fora do seu campo visual gerava-lhes a sensação de preocupação com o RN, afastamento do filho, ansiedade e medo pela separação. Para essas mulheres o modelo de assistência medicalizado, que prioriza basicamente a manutenção da integridade física do RN no pós-parto imediato, remete-lhes à sensação de opressão por serem privadas do contato precoce ao seu concepto.

Outras mulheres, entretanto, eram indiferentes ao fato de o bebê ser afastado para receber os primeiros cuidados e valorizavam esta forma de assistência intervencionista, em função da preocupação com a saúde de seus filhos. Acreditam que esses cuidados são vitais para garantir a integridade física da criança, sendo parte das funções dos profissionais de saúde e que não devem interferir em seu trabalho. A partir de suas descrições, podemos inferir que o parto institucionalizado está arraigado em suas falas como uma prática culturalmente construída.

Um fato preocupante que o estudo revelou foi o número reduzido de consultas do pré-natal que a maioria das mães havia comparecido, cerca de três consultas. Considerando a recomendação do Ministério da Saúde no Programa de Humanização do Pré-natal e Nascimento ${ }^{(17)}$ que preconiza a realização de no mínimo seis consultas de pré-natal durante o processo de gestação, podemos afirmar que estas mulheres tiveram um acompanhamento insuficiente, com prejuízo no seguimento de sua gestação e, consequentemente, nas orientações pertinentes para a ocasião. Em sendo gestantes de baixo risco teriam sido orientadas quanto ao direito de ter um contato precoce com o seu filho, nascendo em boas condições de vitalidade, desde o momento do parto e a importância dessa prática para a aproximação de ambos, conforme recomenda o Manual do Ministério da Saúde ${ }^{(4)}$.

Este resultado está em consonância com um estudo ${ }^{(18)}$ que avaliou a implantação do Programa de Humanização no Pré-natal e Nascimento e constatou que apenas $20 \%$ das mulheres inscritas realizam as seis consultas do pré-natal, apenas $7 \%$ realizam as seis consultas e todos os exames básicos e apenas um pequeno grupo de mulheres recebia a assistência adequada considerando todos os aspectos pontuados no programa.

A análise dos relatos evidenciou que a mulher-mãe vivencia as sensações do processo de gestar e parturição de maneira única e particular. Cabe aos profissionais de saúde, portanto, uma atuação sensível, harmônica e integrada compreendendo toda singularidade que o momento comporta. É importante que suas ações estejam em conformidade com a proposta da humanização da assistência, sendo facilitadores da aproximação entre a mulher e seu concepto, contribuindo, então, para o contato precoce e apego entre a mãe e o RN.

Acreditamos que a prática dos profissionais de saúde que assistem à mulher no momento do parto e, ainda hoje, separam mãe e RN de baixo risco, com medidas extremamente intervencionistas, devam ser repensadas. Torna-se imprescindível que esses trabalhadores revisem suas condutas, muitas vezes rotineiras, a despeito de estudos que comprovam o contrário. Entretanto, concordamos com as auto$\operatorname{ras}^{(14)}$ ao afirmarem que a transformação do modelo assistencial hegemônico vigente não se consolida rapidamente e requer uma mudança de paradigma, crenças, atitudes e práticas. Sabemos, também, que a instituição em que o estudo ocorreu, em sendo um Centro Obstétrico, vivencia um momento de adaptação ao modelo humanista de assistência ao parto e a atuação de enfermeiras obstétricas. Todavia, é importante, também, que a população feminina seja conscientizada dos seus direitos enquanto mulher e mãe, durante a realização do pré-natal e possa vislumbrar na atuação dos profissionais de saúde a garantia de sua integridade física e seu bem-estar emocional. Respeitando esse momento único da mulher e seu concepto, estamos priorizando os princípios da humanização do parto e nascimento, favorecendo a singularidade que este momento comporta.

\section{REFERÊNCIAS}

1. Zveiter M. Contribuições ao documento da Organização Mundial de Saúde (1986): cuidados essenciais ao recém-nascido comentário sobre as implicações psíquicas [dissertação]. Rio de Janeiro: Instituto Fernandes Figueira, Fundação Oswaldo Cruz; 2003.
2. Maldonado MTP. Psicologia na gravidez: parto e puerpério. $11^{\mathrm{a}}$ ed. Petrópolis: Vozes; 1990.

3. Lacava RMVB, Goldman RE, Vieira ES. Cuidados imediatos ao recém-nascido In: Barros SMO, Marin HF, Abrão ACFV, organizadoras. Enfermagem obstétrica e ginecológica: guia para a prática assistencial. São Paulo: Roca; 2002. p. 231-41. 
4. Brasil. Ministério da Saúde. Parto, aborto e puerpério: assistência humanizada à mulher. Brasília; 2001.

5. Dias MAB, Domingues RMSM. Desafios na implantação de uma política de humanização da assistência hospitalar ao parto. Ciênc Saúde Coletiva. 2005;10(3):699-705.

6. Davis-Floyd R. The tecnocratic, humanistic, and holistic paradigms of childbirth. Int J Gynecol Obstet. 2001;75 Suppl 1: S5-23.

7. Montagu A. Tocar: o significado humano da pele. $5^{\text {a }}$ ed. São Paulo: Summus; 1988.

8. Odent M. O renascimento do parto. Florianópolis: Saint Germain; 2002.

9. Whaley LF, Wong DL. Enfermagem pediátrica: elementos essenciais à intervenção efetiva. $5^{\text {a }}$ ed. Rio de Janeiro: Guanabara Koogan; 1999.

10. Gaspareto S, Bussat VR. Necessidade de um trabalho preventivo em maternidade: instruções sobre o comportamento do recém-nascido. Rev Bras Cres Des Hum [periódico na Internet]. 1994[citado 2005 out. 20];(2). Disponível em: http//www.fsp.usp.br/CDH.htm

11. Bardin L. Análise de conteúdo. Lisboa: Edições 70; 1977.
12. Oliveira ZMLP, Madeira AMF. Vivenciando o parto humanizado: um estudo fenomenológico sob a ótica de adolescentes. Rev Esc Enferm USP. 2002;36(2):133-40.

13. Rocha SMM, Simpionato E, Mello DF. Apego mãe-filho: estudo comparativo entre mães de parto normal e cesárea. Rev Bras Enferm. 2003;56(2):125-9.

14. Fernandes K, Kimura AF. Práticas assistenciais em reanimação do recém-nascido no contexto de um centro de parto normal. Rev Esc Enferm USP. 2005;39(4):383-90.

15. Corrêa MAP. Relação mãe-bebê no pós-parto: uma contribuição para a iniciativa do Hospital Amigo da Criança [dissertação]. São Paulo: Programa de Pós-Graduação em Ciências,Secretaria de Estado da Saúde; 2004.

16. Reis AE, Patrício ZM. Aplicação das ações preconizadas pelo Ministério da Saúde para o parto humanizado em um hospital de Santa Catarina. Ciênc Saúde Coletiva. 2005;10 Supl: 221-30.

17. Brasil. Ministério da Saúde. Programa de Humanização no Prénatal e Nascimento. Brasília; 2000.

18. Serruya SJ, Cecatti JG, Lago TG. O programa de humanização no pré-natal e nascimento do Ministério da Saúde no Brasil: resultados iniciais. Cad Saúde Pública. 2004;20(5):1281-9. 